\title{
Sakarya Üniversitesi'nde Robot Yardımlı Laparoskopik Radikal Prostatektomi: Başlangıç Deneyimlerimiz
}

Robot Assisted Laparoscopic Radical Prostatectomy In

Sakarya University: Our Initial Experience

\section{Hacı Ibrahim Çimen, Hacı Can Direk, Fikret Halis, Osman Köse, Ahmet Gökçe, Hasan Salih Sağlam}

Sakarya Üniversitesi, Tıp Fakültesi, Üroloji AD, Sakarya

\author{
Yazışma Adresi / Correspondence: \\ Hacı Ibrahim Çimen \\ Sakarya Üniversitesi, Tıp Fakültesi, Üroloji AD, Sakarya \\ T: +90 $5383928434 \quad$ E-mail: : dr.ibrahimcimen@gmail.com \\ Geliş Tarihi / Received : 23.02.2018 Kabul Tarihi / Accepted : 07.03.2018
}

\begin{abstract}
Öz
Amaç Robot yardımlı laparoskopik radikal prostatektomi (RYLRP) sonuçlarımızı sunmak.

( Sakarya Tip Dergisi 2018, 8(1):134-140 )

Gereç ve Şubat 2015 - Arallk 2017 yilları arasında lokalize prostat kanseri (PCa) nedeniyle Sakarya Üniversitesi'nde RYLRP operasyonu uygulanan Yöntemler hastaların sonuçları retrospektif olarak değerlendirildi.

Bulgular Hastaların ortalama takip süreleri 16,1 (1-36) ay olarak bulundu. Hastaların ortalama yașı $64,04 \pm 6,33$ yl olarak saptand. D'Amico risk sinfflamasına göre hastaların 29 'u $(\% 60,4)$ düşük risk, 13 'ü $(\% 27,1)$ orta risk ve 6 'sı $(\% 12,5)$ yüksek risk sinffinda saptandı. Ortalama operasyon süresi $237,7 \pm 48,07 \mathrm{dk}$, ortalama tahmini kan kaybı 190,4 $\pm 65,8 \mathrm{ml}$ olarak bulundu. Ortalama dren çekilme süresi $3,93 \pm 1,81$ gün, ortalama hastanede kalıs süresi 4,66 $\pm 1,91$ gün, ortalama sonda cekilme süresi $14,1 \pm 2,1$ gün olarak bulundu. On $(\% 20,8)$ hastada cerrahi sinir pozitif saptandı. Kontinans oranları postoperatif 1 . ay, 6 . ay ve 12 . ay'da sirasiyla $\% 50, \% 71,4$ ve $\% 85,2$ olarak bulundu. Potens oranları postoperatif 1 . ay, 6 . ay ve 12 . ay'da sırasıly $\% 37,5, \% 42,9$ ve $\% 51,2$ olarak tespit edildi. Takiplerde 1 hastada biyokimyasal nüks tespit edildi.

Sonuç RYLRP lokalize PCa'nin tedavisinde etkin ve güvenilir bir yöntemdir. Sonuçlarımız literatürle uyumludur. Cerrahi tecrübe arttıkça daha iyi onkolojik ve fonksiyonel sonuçlar alinacaktr.

Anahtar Öğrenme eğrisi; prostat kanseri; robotik cerrahi

Kelimeler:
\end{abstract}

\section{Abstract}

Objective To present our robot assisted laparoscopic radical prosatatectomy (RALRP) results. ( Sakarya Med J 2018, 8(1):134-140 ).

Materials and The results of patients who underwent RALRP between February 2015 and December 2017 for localized prostate cancer (PCa) at Sakarya

Methods University were retrospectively evaluated.

Results IMean follow-up time was 16.1 (1-36) months. The mean patient age was $64.04 \pm 6.33$ years. According to D'Amico risk classification; $29(60.4 \%)$ patients were found to have low risk, $13(27.1 \%)$ patients have moderate risk and $6(12.5 \%)$ patients have high risk. Mean operation time was $237.7 \pm 48.07 \mathrm{~min}$, mean estimated blood loss was $190.4 \pm 65.8 \mathrm{ml}$. Mean draining time was $3.93 \pm 1.81$ days, mean hospitalization time was $4.66 \pm 1.91$ days and mean catheterization time was $14.1 \pm 2.1$ days. Surgical margin positivity was found in 10 (20.8\%) patients. The continent rate at postoperative 1 th, 6 th and 12 th months were $50 \%, 71.4 \%$ and $85.2 \%$; respectively. The potency rates at postoperative 1 th, 6 th and 12 th months were $37.5 \%, 42.9 \%$ and $51.2 \%$; respectively. Biochemical recurrence was detected in 1 patient at follow-up period.

Conclusion RALRP is an effective and reliable method for localized PCa treatment. Our results are consistent with the literature. Better oncologic and functional results will be obtained as surgical experience increases.

Keywords Lurning curve; prostate cancer; robotic surgical procedure 
Sakarya Tıp Dergisi 2018;8(1):134-140

\section{Giriş}

Prostat kanseri (PCa), non-kutanöz tümörler hariç tutulduğunda erkeklerde en sık görülen kanser türüdür ve Amerika Birleşik Devletleri'nde kansere bağlı ölümlerin üçüncü en sık nedenidir. ${ }^{1}$ Prostat spesifik antijen (PSA) testinin artan sıklıkla uygulanması, prostat biyopsi sayısını arttırarak daha fazla PCa tanısı konmasına neden olmaktadır. Bu durum aynı zamanda organa sınırlı PCa tanısını ve buna paralel olarak radikal prostatektomi (RP) adaylarının sayısını da artırmıştır. ${ }^{2}$ RP, organa sınırlı PCa tedavisinde, yaşam beklentisi 10 yılın üstünde olan hastalarda altın standart tedavi seçeneğidir., ${ }^{3,4}$ Bu altın standart yöntem açık, laparoskopik ve robotik olarak uygulanabilir. Robot yardımlı laparoskopik radikal prostatektomi (RYLRP), açık radikal prostatektomiye (ARP) göre daha az invaziv bir yöntemdir ve bu nedenle ARP'ye alternatif olarak karşımıza çıkmaktadır. ${ }^{5}$ Robotik cerrahi 3 boyutlu görüntü sağlamanın yanında robotik enstrümanlar 7 kademeli serbest hareket etme özelliğine sahiptir. Günümüzde ABD'de PCa tedavisinde uygulanan cerrahi prosedürlerin \%60'ından fazlası robotik cerrahi yöntemi ile yapılmaktadır. ${ }^{6}$ RYLRP'nin erken dönem sonuçları değerlendirildiğinde onkolojik, cinsel fonksiyon ve üriner sistem semptomları bakımından ARP ile kıyaslanabilecek sonuçlara sahip olduğu görülmektedir. ${ }^{7-9}$ Bu çalışmada amacımız RYLRP uyguladığımız hastaların sonuçlarını sunmaktır.

\section{Gereç ve yöntemler}

Etik kurul onayı alındıktan sonra Şubat 2015 - Aralık 2017 tarihleri arasında Sakarya Eğitim ve Araştırma Hastanesi Üroloji Kliniği'nde lokalize PCa nedeniyle Da Vinci S cerrahi sistem ile 5 port tranperitoneal posterior yaklaşımla RYLRP uygulanan 48 hastanın verileri retrospektif olarak incelendi. Hastaların yaşı, preoperatif prostat spesifik antijen (PSA), biyopsi gleason skorları, operasyon süresi, tahmini kan kaybı, postoperatif komplikasyonlar, patolojik evre, cerrahi sınır durumu kaydedildi. Hastaların preoperatif ereksiyon durumu Uluslararası Erektil Fonksiyon İndeksi (IIEFEF) doldurtularak değerlendirildi. IIEF-EF skoru 21'in üzerindeki hastalar potens olarak kabul edildi. Postoperatif takiplerde hastalar 1., 6. ve 12. aylarda PSA nüksü, erektil fonksiyon ve kontinans açısından değerlendirildi. Biyokimyasal nüks için PSA sınır değeri 0,2 ng/dl olarak kabul edildi. Hiç bez kullanmayan yada günlük güvenlik pedi kullanan hastalar kontinan olarak kabul edildi. Günlük 2 ped kullanan hastalar hafif, 3 ve üzeri ped kullananlar ise şiddetli inkontinans olarak değerlendirildi. Spontan yada medikal tedavi ile ereksiyonu olmayan ve IIEF-EF skoru 21'in altında olan hastalar impotan olarak kabul edildi. Çalışmada IBM SPSS Statistics 22 programı kullanıldı. Veriler ortalama \pm standart sapma olarak belirtildi.

\section{Bulgular}

Hastaların ortalama takip süreleri 16,1 (1-36) ay olarak bulundu. Hastaların ortalama yaşı 64,04 $\pm 6,33$ yıl olarak saptandı. Ortalama prostat volümü $51,9 \pm 22,7 \mathrm{cc}$, ortalama preop PSA değeri $9,36 \pm 7,8 \mathrm{ng} / \mathrm{ml}$ olarak saptandı. Preop Gleason skoru $35(\% 72,9)$ hastada 6, $12(\% 25)$ hastada 7, $1(\% 2,1)$ hastada 8-10 olarak saptandı. D’Amico risk sınıflamasına göre hastaların 29'u $(\% 60,4)$ düşük risk, 13 'ü $(\% 27,1)$ orta risk ve 6'sı $(\% 12,5)$ yüksek risk sınıfında saptandı.10 Klinik evre; 1 $(\% 2,1)$ hastada T1a, $26(\% 54,2)$ hastada T1c, $17(\% 35,4)$ hastada T2a, $2(\% 4,2)$ hastada T2b, 2 $(\% 4,2)$ hastada T2c olarak saptandı (Tablo 1$)$.

Ortalama operasyon süresi 237,7 \pm 48,07 dk, ortalama tahmini kan kaybı 190,4 \pm 65,8 ml olarak bulundu. Kırk $(\% 83,3)$ hastaya bilateral sinir koruyucu, 1 hastaya $(\% 2,1)$ tek taraflı sinir koruyucu, 
nomogramına göre lenf nodu invazyon olasılığı \%5' in altında olan orta riskli gruptaki 12 hastaya lenf nodu diseksiyonu yapılmadı. ${ }^{11}$

\section{Tablo 1. Hastaların preoperatif bulguları}

\begin{tabular}{|c|c|c|}
\hline $\begin{array}{l}\text { Yaş } \\
\text { ortalama } \pm \text { standart sapma (min.-maks.) }\end{array}$ & & $64,04 \pm 6,33(50-74)$ \\
\hline $\begin{array}{l}\text { Prostat volümü (cc) } \\
\text { ortalama } \pm \text { standart sapma (min.-maks.) }\end{array}$ & & $51,9 \pm 22,7(20-110)$ \\
\hline $\begin{array}{l}\text { PSA değeri }(\mathrm{ng} / \mathrm{dl}) \\
\text { ortalama } \pm \text { standart sapma (min.-maks.) }\end{array}$ & & $9,3 \pm 7,8 \quad(68-39)$ \\
\hline \multirow{3}{*}{ Gleason Skoru, n (\%) } & 6 & $35(72,9)$ \\
\hline & 7 & $12(25)$ \\
\hline & $8-10$ & $1(2,1)$ \\
\hline \multirow{3}{*}{ D’Amico risk sınıflaması, n(\%) } & Düşük & $29(60,4)$ \\
\hline & Orta & $13(27,1)$ \\
\hline & Yüksek & $6(12,5)$ \\
\hline \multirow{5}{*}{ Klinik evre, $n(\%)$} & T1a & $1(2,1)$ \\
\hline & $\mathrm{T} 1 \mathrm{c}$ & $26(54,2)$ \\
\hline & $\mathrm{T} 2 \mathrm{a}$ & $17(35,4)$ \\
\hline & $\mathrm{T} 2 \mathrm{~b}$ & $2(4,2)$ \\
\hline & $\mathrm{T} 2 \mathrm{c}$ & $2(4,2)$ \\
\hline \multirow{2}{*}{ IIEF-EF skoru, n (\%) } & $>21$ & $31(64,6)$ \\
\hline & $<21$ & $17(35,4)$ \\
\hline
\end{tabular}

Diğer tüm hastalara genişletilmiş lenf nodu diseksiyonu yapıldı. Bir hastada intraoperatif end tidal volüm karbondioksit basıncı yüksekliği nedeniyle açık cerrahiye geçildi. Postoperatif $6(\% 12,5)$ hastaya kan transfüzyonu (Clavien grade 2) yapıldı. Açık cerrahiye geçilen hastada postoperatif dönemde akut böbrek yetmezliği (Clavien grade 4) gelişti . Ortalama dren çekilme süresi 3,93 \pm 1,81 gün, ortalama hastanede kalıs süresi 4,66 $\pm 1,91$ gün, ortalama sonda çekilme süresi 14,1 \pm 2,1 gün olarak bulundu (Tablo 2).

Hastaların takiplerinde 1.ay, 6.ay ve 12. ay kontrollerine sırasıyla 48,35 ve 35 hasta ulaştı. Preoperatif dönemde 45 hasta $(\% 93,75)$ kontinan olarak değerlendirilirken, 3 hastanın kontinans durumu kataterize olmaları sebebiyle değerlendirilemedi. Operasyon sonrası 1.ay değerlendirmesinde $24(\% 50)$ hasta kontinan iken, $14(\% 29,2)$ hastada hafif, $10(\% 20,8)$ hastada şiddetli inkontinans tespit edildi. Operasyon sonrası 6.ay değerlendirmesine ulaşan 35 hastanın 25 ’ i $(\% 71,4)$ kontinan iken, $6(\% 17,1)$ hastada hafif, $4(\% 11,4)$ hastada şiddetli inkontinans tespit edildi. Yine 12.ay kontrollerine ulaşan 35 hastanın 30'u $(\% 85,7)$ kontinan iken, $3(\% 8,6)$ hastada hafif, $2(\% 5,7)$ hastada şiddetli inkontinans tespit edildi (Tablo 3).

Preoperatif dönemde $31(\% 64,6)$ hastanın IIEF-EF skoru >21 iken; $17(\% 35,4)$ hastanın IIEF-EF skoru $<21$ idi. Postoperatif 1.,6., ve 12. ay kontrollerinde IIEF-EF $>21$ olan hastaların oranı sırasıyla $\% 37,5, \% 42,9$ ve $\% 51,4$ olarak tespit edildi.

Cerrahi sınır pozitifliği (PSM) saptanan $10(\% 20,8)$ hastaya erken dönemde radyoterapi uygulandı.
Sakarya Tip Dergisi

2018;8(1):134-140

ÇiMEN ve Ark.
Sakarya Üniversitesi'nde Robot Yardımlı Laparoskopik

Radikal Prostatektomi: Başlangıç Deneyimlerimiz 
Sakarya Tıp Dergisi 2018;8(1):134-140

Çimen ve Ark. Sakarya Üniversitesi'nde Robot Yardimlı Laparoskopil Radikal Prostatektomi: Başlangı̧̣ Deneyimlerimiz
Takiplerinde sadece 1 (\%2) hastada PSA nüksü tespit edildi.

\begin{tabular}{|c|c|c|}
\hline $\begin{array}{l}\text { Operasyon süresi, dk } \\
\text { ortalama } \pm \text { standart sapma (min.-maks.) }\end{array}$ & & $237,7 \pm 48(180-350)$ \\
\hline $\begin{array}{l}\text { Ortalama kan kaybı, ml } \\
\text { ortalama } \pm \text { standart sapma (min.-maks.) }\end{array}$ & & $190,4 \pm 65,8(90-320)$ \\
\hline \multirow{3}{*}{ Postoperatif Gleason skoru; n (\%) } & 6 & $22(45,8)$ \\
\hline & 7 & $20(41,7)$ \\
\hline & $8-10$ & $5(11,4)$ \\
\hline \multirow{6}{*}{ Patolojik evre; n (\%) } & T0 & $1(2,1)$ \\
\hline & T2a & $7(14,6)$ \\
\hline & $\mathrm{T} 2 \mathrm{~b}$ & $2(4,2)$ \\
\hline & $\mathrm{T} 2 \mathrm{c}$ & $21(43,7)$ \\
\hline & T3a & $15(31,3)$ \\
\hline & $\mathrm{T} 3 \mathrm{~b}$ & $2(4,2)$ \\
\hline \multirow{2}{*}{ Cerrahi sınır durumu; n (\%) } & Pozitif & $10(20,8)$ \\
\hline & Negatif & $38(79,2)$ \\
\hline \multirow{2}{*}{ Clavien komplikasyon; n (\%) } & 2 & $6(12,5)$ \\
\hline & 4 & $1(2,1)$ \\
\hline $\begin{array}{l}\text { Ortalama dren çekilme süresi; gün } \\
\text { ortalama } \pm \text { standart sapma }\end{array}$ & & $3,93 \pm 1,81$ \\
\hline $\begin{array}{l}\text { Ortalama hospitalizasyon süresi; gün } \\
\text { ortalama } \pm \text { standart sapma }\end{array}$ & & $4,66 \pm 1,91$ \\
\hline $\begin{array}{l}\text { Ortalama sonda çekim süresi; gün } \\
\text { ortalama } \pm \text { standart sapma }\end{array}$ & & $14,1 \pm 2,1$ \\
\hline
\end{tabular}

Tablo 3. Hastaların operasyon öncesi ve sonrası takiplerinde kontinans ve erektil fonksiyon durumları

\begin{tabular}{|l|l|l|l|l|l|}
\hline & & $\begin{array}{l}\text { Preoperatif } \\
\text { dönem }\end{array}$ & Postop 1.ay & Postop 6.ay & Postop 12.ay \\
\hline \multicolumn{2}{|l|}{ Kontinan, (\%) } & $45(93,75)$ & $24(50)$ & $25(71,4)$ & $30(85,7)$ \\
\hline \multirow{2}{*}{ İnkontinan, (\%) } & Hafif & & $14(29,2)$ & $6(17,1)$ & $3(8,6)$ \\
\cline { 2 - 6 } & Şiddetli & & $10(20,8)$ & $4(11,4)$ & $2(5,7)$ \\
\hline IIEF $>21,(\%)$ & $31(64,6)$ & $18(37,5)$ & $15(42,9)$ & $18(51,4)$ \\
\hline IIEF <21, (\%) & $17(35,4)$ & $30(62,5)$ & $20(57,1)$ & $17(48,6)$ \\
\hline \multicolumn{2}{|l|}{ IIEF: Uluslararası Erektil Fonksiyon Indeksi }
\end{tabular}

\section{Tartışma}

RP operasyonu ilk olarak 1905 yılında Hugh Hampton Young tarafından tanımlanmış, organın derin yerleşimli ve güçlü bir vasküler ağa sahip olması nedeniyle çok tecrübeli cerrahlara dahi zorluklar çıkarmıştır. Bu teknik zorluklar ciddi cerrahi morbidite ve mortalite olarak karşımıza çıkmıştır. Süregelen dönemlerde cerrahi prosedürler tekrar tanımlanmış, morbidite ve mortalite giderek azalmıştır. Günümüzde morbiditeyi daha da azaltmak için daha az invaziv prosedürler tanımlanmaya devam etmektedir.

ARP'ye göre daha az invaziv teknik olarak gösterilen RYLRP sırasında meydana gelen kan kaybının çoğunluğu venöz sinüslerden kaynaklanmaktadır. Menon ve arkadaşlarının ilk 30 RYLRP serisinde ortalama kan kaybı 329 ml ve kan transfüzyon oranı \%7 olarak rapor edilmiş ve istatistiksel olarak 
ARP’ye göre düşük bulunmuştur. ${ }^{12}$ Fracalanza ve arkadaşlarının ilk 35 vakalık serisinde ise ortalama kan kaybı $300 \mathrm{ml}$ ve kan transfüzyon oranı \%17 olarak rapor edilmiş ve istatistiksel olarak kendi ARP serilerinden düşük bulunmuştur. ${ }^{13}$ Yüksek transfüzyon oranlarına sahip ilk serilerin devamında RYLRP'de transfüzyon oranları \%0,5'lere kadar düşmüş ve yine istatistiksel olarak ARP serilerinden düşük bulunmuştur. ${ }^{14}$ ilk deneyimlerimizi yayınladığımız çalışmamızda tahmini kan kaybı 190,4 \pm $65,8 \mathrm{ml}$, transfüzyon oranı $\% 12,5$ olarak bulunmuş olup literatürdeki ilk serilerle benzerlik göstermektedir.

Karşılaştırmalı vaka serilerinde öğrenme eğrisinde yapılan RYLRP cerrahi süresinin ARP’ye göre uzun ancak laparoskopik tekniğe göre kısa olduğu gösterilmiştir. ${ }^{15}$ Menon ve ark. ilk 40 RYLRP serisinde ortalama operasyon süresi $276 \mathrm{dk}$, Joseph ve ark ilk 50 RYLRP serisinde ise $202 \mathrm{dk}$ olarak rapor edilmiştir. ${ }^{16,17}$ Literatürde tecrübe arttıkça operasyon süresinin genellikle 3 saatin altında olduğuna dair çalışmalar mevcuttur.18-20 Bizim çalışmamızda ortalama operasyon süresi 237,7 \pm 48,07 dk olarak bulunmuş ve tecrübe artıkça bu sürenin azaldığı gözlenmiştir.

RYLRP 1. yıl kontinans oranları yapılan çalışmalarda \%82-95 arasında değerlerde bulunmuş ve kontinans oranının operasyondan sonra zamanla arttığı gözlenmiştir. ${ }^{21}$ Zorn ve ark 300 hastalık vaka serilerinde 1 . ay , 6 . ay ve 12 . ay kontinans oranlarını sırasıyla $\% 23, \% 68$ ve $\% 90$ olarak rapor etmişler ve interfasyal sinir korumanın kontinansa olumlu etkisinin olduğunu raporlamışlardır.22 Ahlering ve ark. tek cerrah tarafından yapılan ve öğrenme eğrisindeki vakaların çalışma dışı bırakıldığı 60 hastalık RYLRP serisinde 3. ay kontinans oranını \%76 olarak raporlamışlardır.23 Menon ve ark. anastomoz tekniklerini karşılaştırdıkları çalışmasında 1. ay kontinans oranını tek tabaka anastomoz yaptıkları grupta $\% 74$, çift tabaka anastomoz yaptıkları grupta ise $\% 80$ olarak tespit etmişlerdir. ${ }^{24}$ Tewari ve ark. puboprostatik ligamanların korunduğu çalışmasında 3. ay kontinans oranlarını \%88 olarak raporlamışlardır. ${ }^{25}$ Krambeck ve ark. ARP ile karşılaştırmalı çalışmasında 1. yıl kontinans oranını \%91 olarak rapor etmişlerdir. ${ }^{26}$ Literatürdeki bu farklılığın kontinans tanımlamasının farklı olması ve kullanılan değerlendirme anketlerinin farklı olmasından kaynaklanabileceği düşünülmüştür.

Çalışmamızda hiç bez kullanmayan yada günlük güvenlik pedi kullanan hastalar kontinan olarak kabul edildi. Günlük 2 ped kullanan hastalar hafif, 3 ve üzeri ped kullananlar ise şiddetli inkontinan olarak değerlendirildi. Hastalar 1., 6. ve 12. aylarda buna göre sorgulanarak değerlendirme yapılmıştır. Operasyon sonrası 1. ay değerlendirmesinde $24(\% 50)$ hasta kontinan iken $14(\% 29,2)$ hastada hafif $10(\% 20,8)$ hastada şiddetli inkontinans tespit edildi. Operasyon sonrası 6.ay değerlendirmesine ulaşan 35 hastanın 25 (\%71,4)'i kontinan iken, $6(\% 17,1)$ hastada hafif $4(\% 11,4)$ hastada şiddetli inkontinans tespit edildi. Yine 12.ay kontrollerine ulaşan 35 hastada; $30(\% 85,7)$ hasta kontinan iken, $3(\% 8,6)$ hastada hafif, $2(\% 5,7)$ hastada şiddetli inkontinans tespit edildi. Kontinans oranlarımız öğrenme eğrisindeki vakalarımızın sonuçları olmasına rağmen literatürle benzer bulundu.

Radikal prostatektomi sonrası erektil fonksiyonun korunması nörovasküler demetin (NVD) içinde bulunan kavernöz sinirin prostat bezinden tam ve titizlikle ayrılmasına bağlıdır. ${ }^{27}$ Laparoskopik ve robotik yöntemle yapılan prostatektomide operasyon alanının büyütülmüş görüntüsünün sağlanması ve NVD'nin daha az travmatik ve daha doğru diseksiyonunu sağlayarak daha iyi postoperatif erektil fonksiyona neden olduğu düşünülmektedir. Fakat her iki yöntemin de açık cerrahiye göre
Sakarya Tıp Dergisi

2018;8(1):134-140

ÇiMEN ve Ark.

Sakarya Üniversitesi'nde Robot Yardımlı Laparoskopik

Radikal Prostatektomi: Başlangıç Deneyimlerimiz 
Sakarya Tıp Dergisi 2018;8(1):134-140 erektil fonksiyonu daha iyi koruduğuna dair yayınlanmış bir çalışma yoktur.

Yapılmış olan çalışmalarda robotik radikal prostatektomi sonrası potens oranları Patel ve ark. \%78, Zorn ve ark. \%80, Tewari ve ark. \%87 olarak bulmuşlardır. ${ }^{20,22,25}$ Bahsi geçen çalışmalarda potens oranlarının bizim çalışmamıza göre yüksek olmasının sebebi olarak, bu çalışmalarda sadece preoperatif dönemde de potens olan hastaların hesaba katılması olabilir. Örneğin Patel ve ark'nın ilk 500 vakalık serilerinde belirtmiş oldukları $\% 78$ 'lik potens oranı preoperatif dönemde potens olan 200 hastaya aittir. Bizim bu çalışmamızda preoperatif dönemde potent olan 31 hastamız mevcut olup, bu hastların 1 . ayda $18(\% 58,6)$ 'i potensini sürdürmüştür.

RYLRP'nin gerçek başarısını gösterecek olan veri uzun dönemdeki onkolojik sonuçlardır. Biyokimyasal nükssüz sağ kalım yöntemin etkinliğini gösteren nihai yöntemdir. PSM PSA rekürrensi için öngörücüdür. Menon ve ark. binden fazla sayıda hasta içeren serilerinde toplam \%9 PSM oranı bildirirken, Cathelineau ve ark. Avrupa deneyimi olarak yayınladıkları serilerinde bu oran $\% 22$ olarak rapor edilmiştir. ${ }^{28,29}$ Bizim serimizde PSM oranı \%20,8 olarak bulunmuş ve öğrenme eğrisinde yayınlanan serilerle benzer olduğu görülmüştür. Cerrahi sınır pozitifliği saptadığımız 10 hastaya postoperatif erken dönemde radyoterapi uygulanmış ve sadece 1 (\%2) hastada biyokimyasal nüks saptanmışır.

\section{Sonuç}

RYLRP lokalize PCa'nin tedavisinde etkin ve güvenilir bir yöntemdir. Sonuçlarımız literatürle uyumludur. Cerrahi tecrübe arttıkça daha iyi onkolojik ve fonksiyonel sonuçlar alınacaktır. 
1. Siegel RL, Miller KD, Jemal A. Cancer statistics, 2017. CA Cancer J Clin 2017; 67(1):

2. Schröder FH, Carter HB, Wolters T, van den Berg RC, Gosselaar C, Bangma $\mathrm{CH}$ et al. Early detection of prostate cancer in 2007. Part 1: PSA and PSA kinetics. Eur Urol 2008; 53(3): 468-77.

3. Walsh PC. Anatomic Radical Retropubic Prostatectomy; in Walsh PC, Retik AB, Vaughan ED, Wein AJ(Eds.): Campbell's Urology 7th Edition, 1998: 2565-88.

4. Bianco FJJr, Scardino PT, Eastham JA. Radical prostatectomy: longterm cancer control and recovery of sexual and urinary function ("trifecta"). Urology 2005; 66: 83-94. [CrossRef]

5. Binder J, Brautigam R, Jonas D, Bentas W. Robotic surgery in urology: fact or fantasy BJU international 2004;94:1183-1187.

6. Hu JC, Gu X, Lipsitz SR, Barry MJ, D’Amico AV, Weinberg AC et al. Comparative effectiveness of minimally invasive vs open radical prostatectomy. JAMA 2009;302:1557-1564.

7. Duffey B, Varda B, Konety B. Quality of evidence to compare outcomes of open and robot-assisted laparoscopic prostatectomy. Current urology reports 2011;12:229-236.

8. Kang DC, Hardee MJ, Fesperman SF, Stoffs TL, Dahm P. Low quality of evidence for robot-assisted laparoscopic prostatectomy: results of a systematic review of the published literature. European urology 2010;57:930-937.

9. Lowrance WT, Tarin TV, Shariat SF. Evidence-based comparison of robotic and open radical prostatectomy. TheScientificWorldjournal. 2010;10:2228-2237

10. Cooperberg MR, Pasta DJ, Elkin EP, Litwin MS, Latini DM, Du Chane J et al. The University of California, San Francisco Cancer of the Prostate Risk Assessment score: a straightforward and reliable preoperative predictor of disease recurrence after radical prostatectomy. J Urol 2005, 173(6): 1938-42.

11. Eifler JB, Feng Z, Lin BM, Partin MT, Humphreys EB, Han M et al. An updated prostate cancer staging nomogram (Partin tables) based on cases from 2006 to 2011. BJU Int. 2013 Jan;111(1):22-9. doi: 10.1111/j.1464-410X.2012.11324.x. Epub 2012 Jul 26.

12.Menon M, Tewari A, Baize B, Guillonneau B, Vallancien G. Prospective comparison of radical retropubic prostatectomy and robot-assisted anatomic prostatectomy: the Vattiku Urology Institute experience. Urology 2002; 60(5):864-8.

13. Fracalanza S, Ficarra V, Cavalleri S, Galfano A, Novara G, Mangano A, et al. Is robotically assisted laparoscopic radical prostatectomy less invasive than retropubic radical prostatectomy? Results from a prospective, unrandomized, comparative study. BJU Int 2008; 101(9):1145-9.

14.Farnham SB, Webster TM, Herrell SD, Smith JA Jr. Intraoperative blood loss and transfusion requirements for robotic-assisted radical prostatectomy versus radical retropubic prostatectomy. Urology 2006;67:360-3.

15. Ficarra V, Novara G, Artibani W, Cestari A, Galfano A, Graefen M et al. Retropubik, laparoskopik and robot-assisted radical prostatectomy: a systematic review and cumulative analysis of comparative studies. Eur Urol 2009; 55:1037-63.

16. Menon M, Shrivastava A, Tewari A, Sarle R, Hemal A, Peabody JO et al. Laparoscopic and robot assisted radical prostatectomy: establishment of a structured program and preliminary analysis of outcomes. J Urol 2002;168:945-9.

17. Joseph JV, Vicente I, Madeb R, Erturk E, Patel HR. Robot- assisted versus pure laparoscopic radical prostatectomy: are there any differences? BJU Int 2005;96:39-42.

18. Menon M, Shrivastava A, Kaul S, Badani KK, Fumo M, Bhandari M et al. Vattikuti Institute prostatectomy: contemporary technique and analysis of results. Eur Urol 2007; 51(3):648-57.

19. Mottrie A, Van Migem P, De Naeyer G, Schatteman P, Carpentier P, Fonteyne E. Robot-assisted laparoscopic radical prostatectomy: oncologic and functional results of 184 cases. Eur Urol 2007; 2:746-51.

20.Patel VR, Thaly R, Shah K. Robotic radical prostatectomy: outcomes of 500 cases. BJU Int 2007; 99:1109-12.

21. Kural AR, Atuğ F. The applications of robotic surgery in urology. Turkish Journal of Urology 2010; 36: 248-57. [CrossRef]

22.Zorn KC, Gofrit ON, Orvieto MA, Mikhail AA, Zagaja GP, Shalhav AL. Robotic- assisted laparoscopic prostatectomy: functional and pathologic outcomes with interfascial nerve preservation. Eur Urol 2007; 51: 755-63.

23. Ahlering TE, Wood D, Eichel L, Lee DI, Edwards R, Skarecky DW. Robot-assisted versus open radical prostatectomy: a comparison of one surgeon's outcomes. Urology 2004b;63:819-22.
24. Menon M, Muhletaler F, Campos M, Peabody JO. Assessment of early continence after reconstruction of the periprostatic tissues in patients undergoing computer assisted (robotic) prostatectomy: results of a 2 group parallel randomized controlled trial. J Urol 2008;180:1018-23.

25. Tewari AK, Bigelow K, Rao S, Takenaka A, El-Tabi N, Te A et al. Anatomic restoration technique of continence mechanism and preservation of puboprostatic collar: a novel modification to achieve early urinary continence in men undergoing robotic prostatectomy. Urology 2007;69:726-31.

26. Krambeck AE, DiMarco DS, Rangel LJ, Bergstralh EJ, Myers RP, Blute ML et al. Radical prostatectomy for prostatic adenocarcinoma: a matched comparison of open retropubic and robot-assisted techniques. BJU Int 2009;103:448-52.

27. Walsh PC, Donker PJ. Impotence following radical prostatectomy: in sight into etiology and prevention. J Urol 1982;128:492-7.

28. Menon M, Tewari A, Peabody J, Shrivastava A, Kaul S, Bhandari A et al. Vattikuti Institute prostatectomy, a technique of robotic radical prostatectomy for management of localized carcinoma of the prostate experience of over 1100 cases. Urol Clin North Am 2004; 31: 701-7.

29. Cathelineau X, Rozet F, Vallancien G. Robotic radical prostatectomy: the European experience. Urol Clin North Am; 31: 693-9.
Sakarya Tip Dergis 2018;8(1):134-140

\section{ÇIMEN ve Ark.}

Sakarya Üniversitesi nde Robot Yardımlı Laparoskopik Radikal Prostatektomi: Başlangıç Deneyimlerimiz 